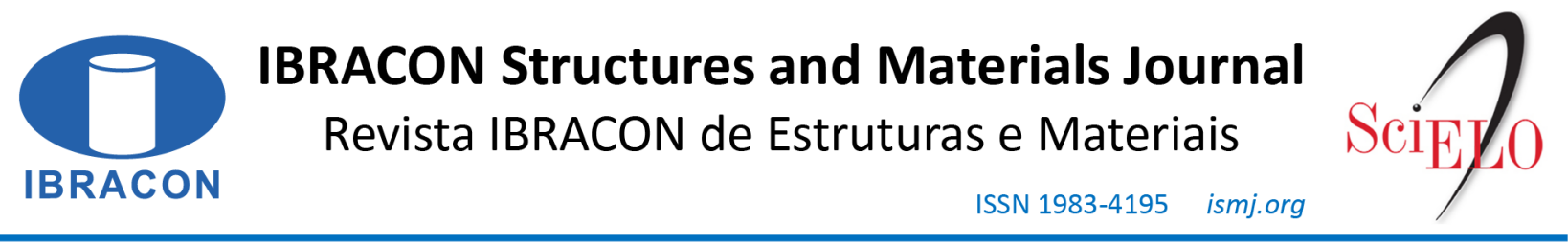

ORIGINAL ARTICLE

\title{
Development and validation of an ultrasound imaging software for nondestructive evaluation of concrete pavements
}

\section{Desenvolvimento e validação de um software de formação de imagem de ultrassom para avaliação estrutural não-destrutiva de pavimentos de concreto}

\author{
Henrique Luiz de Lima Seiffert ${ }^{\mathrm{a}}$ \\ José Tadeu Balbo ${ }^{\mathrm{a}}$ (D)
}

${ }^{a}$ Universidade de São Paulo - USP, Escola Politécnica, Departamento de Engenharia de Transportes, São Paulo, SP, Brasil

Received 23 July 2020

Accepted 04 January 2021

\begin{abstract}
A Synthetic Aperture Focusing Technique-based ultrasound imaging software was developed and validated in this work. The software development process was discussed in detail. For validation, Jointed Plain Concrete Pavements were imaged with the evaluated software and a software assumed to yield standard images. The quality of the standard and evaluated images were analyzed and compared. The backwalls and dowels were recognizable in the standard and evaluated images. The thickness estimates obtained with each software was the same. The characteristics of objects and artifacts were explained in terms of the technology's fundamentals and its implementations' characteristics. The evaluated software resulted, therefore, in images of similar quality to the standard software's images from a practical standpoint. The herein developed software was then validated for research on nondestructive evaluation of concrete pavements and can be used for testing and development of performance-improving signal and image processing techniques.
\end{abstract}

Keywords: concrete pavements, nondestructive evaluation, ultrasound imaging.

Resumo: Um software de formação de imagem de ultrassom baseado na Synthetic Aperture Focusing Technique foi desenvolvido e validado neste trabalho. O desenvolvimento do software foi discutido em detalhes. Para validação, Pavimentos de Concreto Simples foram imageados com o software avaliado e um software que resulta em imagens consideradas referência. A qualidade das imagens avaliadas e referências foram analisadas e comparadas. As backwalls e a barras metálicas eram reconhecíveis nas imagens avaliadas e referências. As estimativas de espessura obtidas com os dois softwares eram iguais. As características dos objetos e artefatos nas imagens foram explicadas em termos dos fundamentos da tecnologia e das características de suas implementações. O software avaliado resultou, portanto, em imagens de qualidade similar àquelas do software referência para fins práticos. O software desenvolvido aqui foi, logo, validado e poderá ser utilizado para pesquisa sobre avaliação estrutural não-destrutiva de pavimentos de concreto e para teste e desenvolvimento de técnicas de processamento de sinais e imagens para melhorar o desempenho da tecnologia.

Palavras-chave: pavimentos de concreto, avaliação estrutural não-destrutiva, imagem de ultrassom.

How to cite: H. L. L. Seiffert and J. T. Balbo, "Development and validation of an ultrasound imaging software for nondestructive evaluation of concrete pavements," Rev. IBRACON Estrut. Mater., vol. 14, no. 5, e14511, 2021, https://doi.org/10.1590/S1983-41952021000500011

\section{INTRODUCTION}

To select a method for nondestructive evaluation (NDE) of a given concrete structure, the penetration depth, resolution, signal-to-noise ratio (SNR), and application record of prospective methods should be taken into consideration [1]. Based on this, a good method for Jointed Plain Concrete Pavement (JPCP) NDE would be ultrasound imaging (UI) with the Synthetic Aperture Focusing Technique (SAFT). 
The SAFT is an UI algorithm that tackles resolution and noise-related issues hindering conventional concrete UI and offers a better compromise among SNR, resolution, and penetration depth [2], [3]. SAFT UI has been successfully used to recognize steel bars, ducts, delamination, air voids, and cracks in concrete pavements [4]-[7] and other concrete structures [8]-[10].

Nevertheless, JPCP NDE with SAFT UI has been hindered by efficiency and accuracy-related issues [11]. It could be bolstered, therefore, with signal and image processing techniques that improve its efficiency and accuracy [12]-[14]. The development and application of such techniques both require, however, a validated and extensible SAFT UI software; that is, a software that outputs good-quality images within the SAFT's limitations at any time and where those techniques could eventually be plugged in.

A SAFT UI software with these characteristics was developed and validated in this work. The software development process was presented in detail. JPCPs were imaged with the herein developed software and the SAFT UI software accompanying the data acquisition device used in this work. The quality of their images was evaluated from a practical standpoint, and the similarities and differences in image quality were used to validate the herein developed software assuming that the other one yields standard images. The characteristics of the objects and artifacts in the images were discussed to explain image quality and differences between the software.

As previously mentioned, the development of such solutions is requisite for employing or developing performanceimproving techniques and therefore, to make the most of the technology for a given application. This work's discussion on image characteristics and their relationship to the algorithm's fundamentals and its implementation's characteristics should be relevant for developing and validation similar solutions for any application. Nevertheless, a general framework for validating such solutions is not presented in this work.

The SAFT is reviewed in the next section. The herein developed software is presented subsequently. The validation process and its results are presented and discussed next, followed by this work's conclusions.

\section{SYNTHETIC APERTURE FOCUSING TECHNIQUE}

The SAFT processes ${ }_{\text {I }}$ signals $\mathrm{g}_{\mathrm{i}}(\mathrm{t}), \mathrm{i}=1,2,3, \ldots, \mathrm{I}$, acquired in the pulse-echo or pitch-catch inspection of a concrete volume of interest and outputs an image $f(x, y)$ of this volume. To this purpose, the inspected volume is first represented as ${ }_{\mathrm{I}}$ rectangular grids $\mathrm{f}_{\mathrm{i}}(\mathrm{x}, \mathrm{y})$ (reconstruction grid) with rectangular grid elements $\mathrm{P}(\mathrm{x}, \mathrm{y})$ (Figure 1).
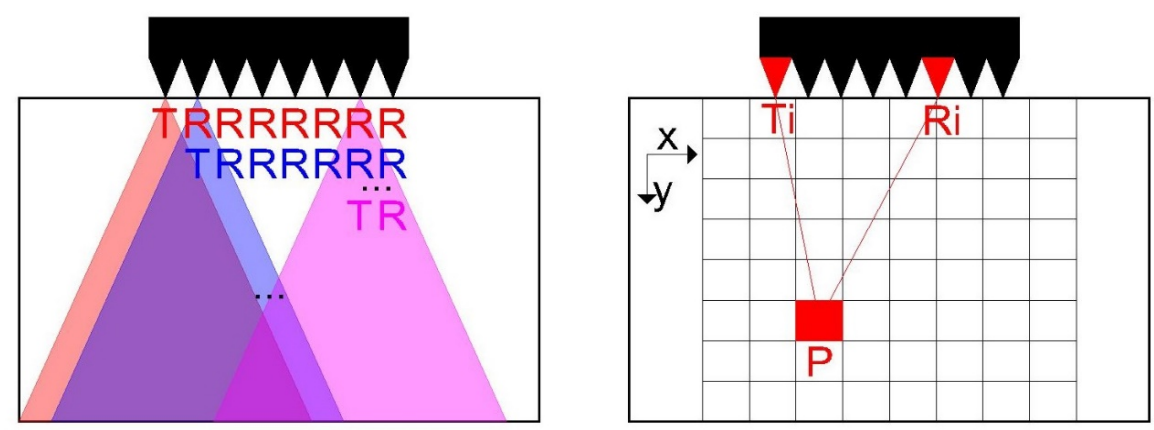

Figure 1. Data acquisition device's operation mode (left) and geometry assumed for ultrasound imaging (right).

The signals $g_{i}(t)$ contain the pressure amplitude of reflected waves (and other waves) as a function of time. The SAFT first maps this time-domain information into space. In the mapping process, the amplitude of $g_{i}(t)$ at a time instant $t^{*}, g_{i}\left(t^{*}\right)$, is ascribed to a grid element $P(x, y)$ of $f_{i}(x, y)$ with Equations 1 and 2. Equation 2 assumes that an ultrasound wave was transmitted into the concrete at $T_{i}\left(x_{T}, y_{T}\right)$, reflected at $P(x, y)$, and then sensed at $R_{i}\left(x_{R}, y_{R}\right)$ in $t^{*}$ time units, where $T_{i}$ and $R_{i}$ are the positions of the transducers at transmission and reception mode, respectively. It also assumes ray-like wave propagation, constant propagation speed $c$, and specular reflection at $P(x, y) \cdot t_{d}$ is the system's delay. After every $P(x, y)$ of every $f_{i}(x, y)$ had a pressure amplitude ascribed to it, the $f_{i}(x, y)$ are summed up with Equation 3 to obtain $f(x, y)$ [3], [15]. 
$f_{i}(x, y)=g_{i}\left(t^{*}\right)$

$t^{*}=t_{d}+c^{-1}\left[\sqrt{\left(x_{T}-x\right)^{2}+\left(y_{T}-y\right)^{2}}+\sqrt{\left(x_{R}-x\right)^{2}+\left(y_{R}-y\right)^{2}}\right]$

$f(x, y)=\sum_{i=1}^{I} f_{i}(x, y)$

The SAFT yields higher-quality images because the best achievable resolution is achieved everywhere in the image plane [15] and reflecting objects, e.g. backwall, steel bars, and defects, are enhanced, whereas noise, including structural noise, is reduced [2], [3]. In Equation 3, the amplitudes of different signals mapped to the same position are superimposed. If these amplitudes are in phase, as expected for reflecting objects, then there will be constructive interference among them and enhancement of such objects in $f(x, y)$. The opposite takes place for the background noise, since noise components in different signals are generally not in phase [2], [16]-[18]. Therefore, SNR and resolution are enhanced [2], [3], [19].

Nevertheless, from a practical standpoint, image quality might be hindered by the SAFT's assumptions. The pulse velocity ${ }_{c}$ is not constant across the image plane since concrete is a dispersive medium [3]; hence, objects might be shown with wrong shape or position in $\mathrm{f}(\mathrm{x}, \mathrm{y})$ [20]. The implications of attenuation are disregarded; hence, the brightness of objects in $f(x, y)$ might not be proportional to their elastic properties [13]. Consequently, objects might not be shown as expected and their recognition might be hindered despite the SNR and resolution enhancements.

Moreover, every signal component is assumed a one-time reflected wave. Therefore, artifacts might arise from phenomena such as multiple reflections [9] and surface waves [13], [21] that make up the signals but are disregarded. Further artifacts might arise from mode conversion [3] and acoustic shadowing [4]. Acoustic shadowing occurs when objects of interest behind reflecting objects (e.g. steel bars) are not shown in $f(x, y)$ because not enough energy was transmitted across these objects [20].

\section{SOFTWARE DEVELOPMENT}

The SAFT was implemented in MATLAB R2015a (MathWorks, Natick, USA) with some amendments. The width of the grids $f_{i}(x, y)$ should be approximately the distance between the outermost transducers and their depth should be more than the inspected structure's thickness. The size of our $f(x, y)$ and $f_{i}(x, y)$ were 500 by $500 \mathrm{~mm}$. The dimensions of the grid elements $\mathrm{P}(\mathrm{x}, \mathrm{y})$ should be proportional to inspection system's sampling frequency [22]. The size of our $\mathrm{P}(\mathrm{x}, \mathrm{y})$ were 1 by $1 \mathrm{~mm}$.

The transducers positions $T_{i}\left(x_{T}, y_{T}\right)$ and $R_{i}\left(x_{R}, y_{R}\right)$ for each $g_{i}(t)$ should be known with precision. The data acquisition device used in this work was an array with fixed elements and known operation mode; therefore, $T_{i}$ and $R_{i}$ were easily determined from the device's characteristics. As the transducers are on the structure's surface, it was assumed that $y_{T}=y_{R}=0$. The value of $c$ should be assumed or estimated with testing or signal processing. The $c$ value estimated by the data acquisition device from the arrival time of surface waves was used in this work [14]. The values of $t^{*}$ determined from Equation 2 are real but the values of $t_{t}$ are integer multiples of the sampling period. The floor function was selected to determine the sample of $g_{i}(t)$ corresponding to $t^{*}$. The signals were not rectified, to preserve the phase information used in Equation 3 [23], and were not pre-processed either.

The SAFT assumes in Equation 2 that the entire concrete volume was insonified by every $T_{i}$ [17]. Since this is not true, the windowing function $\mathrm{w}_{\mathrm{i}}(\mathrm{x}, \mathrm{y})$ in Equation 4 [12] was used to consider the volume portion that was insonified by each $T_{i}$. Essentially, $w_{i}(x, y)$ weights the amplitudes mapped to $f_{i}(x, y)$ assuming a beam spreading function. Equation 5 was used instead of Equation 3.

$w_{i}=\frac{\left(y-y_{T}\right)}{\sqrt{\left(x_{T}-x\right)^{2}+\left(y_{T}-y\right)^{2}}} \frac{\left(y-y_{R}\right)}{\sqrt{\left(x_{R}-x\right)^{2}+\left(y_{R}-y\right)^{2}}}$

$f(x, y)=\sum_{i=1}^{N} f_{i}(x, y) w_{i}(x, y)$ 
Additionally, the upper envelope of each column of $f(x, y)$ was determined with the Hilbert transform and taken as its new values [12]. $f(x, y)$ was then transformed into a grayscale image, outputted, and displayed with a color scheme where pixel brightness is proportional to color warmness. Though the signals were not processed prior to mapping and $f(x, y)$ was not processed after transformation with performance-improving techniques, modules for this could be easily added to the software.

\section{SOFTWARE VALIDATION}

\subsection{Data acquisition}

The JPCP test section (TS) and the concrete slab (CS) imitating doweled regions of JPCPs in Figure 2 were both imaged in this work. TS comprised $250 \mathrm{~mm}$-thick concrete slabs, was built in 1999, and, according to visual inspections [24], was in sound condition at data acquisition. Its as-built thickness was measured with coring right after data acquisition. The CS was $190 \mathrm{~mm}$ thick (in design and after construction) and had three $25 \mathrm{~mm}$ steel bars inserted 54, 74, and $94 \mathrm{~mm}$ deep. It was built in laboratory in 2019; dowel positioning was ensured by tying the dowels to trusses and the trusses to the forms. The TS' and CS' concrete mixes are presented in Table 1.
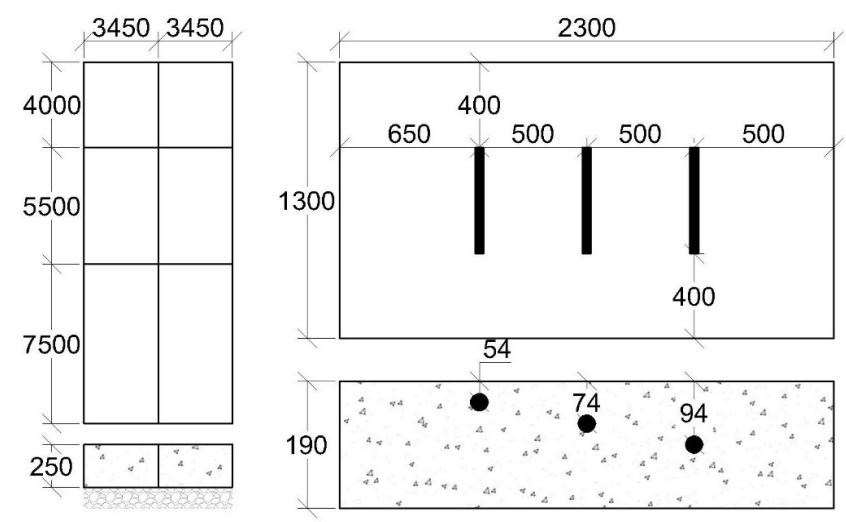

Figure 2. TS' (left) and CS' (right) designs (Units: mm.)

Table 1. TS' and CS' concrete mixes.

\begin{tabular}{ccc}
\hline Component & Proportion in TS $\left(\mathbf{k g} / \mathbf{m}^{\mathbf{3}}\right)$ & Proportion in CS $\left(\mathbf{k g} / \mathbf{m}^{\mathbf{3}}\right)$ \\
\hline Cement & 383 & 375 \\
\hline Sand & 638 & 807 \\
\hline Gravel & 1215 & 1126 \\
\hline Water & 172 & 175 \\
\hline Plasticizer & 1.34 & 2.06 \\
\hline
\end{tabular}

Data was acquired on six points on the TS in 2018 and nine points on the CS in 2019. The TS' points were on plain regions. The CS' points were three over each dowel's axis. The number of points was deemed sufficient since this work aimed to validate the software for research purposes and the scenarios of interest were restricted to plain and doweled regions of sound JPCPs. A larger and more diverse set of points should be used to validate similar software for practical purposes or for a large set of scenarios. A practical obstacle for increasing the number and diversity of points for any purpose is the fact that a structure's as-built characteristics must be known with precision for validation.

The data acquisition process was the same for every point. The area where the data acquisition device would be placed was swept free of debris and a point was marked with a construction pencil. The device was positioned centered on the point and data acquisition was carried out. A coupling layer or surface preparation was not required. The acquired data was labelled, stored in the device, and eventually transferred to a personal computer for processing.

ACSYS' A1040 MIRA was the data acquisition device. It comprises a 4-by-12 array of transducers operated as a 1-by-12 one. Its transducers are $30 \mathrm{~mm}$ apart and transmit $50 \mathrm{kHz}$ shear-horizontal waves. Its operation mode is illustrated in Figure 1. Each transducer, except the rightmost one, is operated in transmission ( $~_{\mathrm{r}}$ ) once, while the transducers to its right are in reception 
mode $(R)$. The transducer ${ }_{T}$ is switched from left to right to sweep the concrete volume beneath the device. A signal $g_{i}(t)$ is acquired for each ${ }_{\mathrm{T}-\mathrm{R}}$ pair. $\mathrm{I}=66$ signals are acquired on each point then. The device also estimates the pulse velocity $\mathrm{c}$ in the inspected concrete volume with the time-of-flight of surface waves [14].

\subsection{Validation procedure}

The TS' and CS' data were inputted to the herein developed software and the SAFT UI software accompanying the data acquisition device. The latter was assumed to result in standard images since it was developed for practical purposes. Its images are hereafter called standard images, while the images obtained with the software being validated are called evaluated images.

The herein developed software was evaluated by comparing the quality of its images to the standard ones. The images were analyzed from a practical standpoint. A good-quality image was assumed to be one where the backwall and dowel were recognizable and positioned correctly. An object was assumed recognizable if it was shown with the expected shape and brightness and around their expected positions. Artifacts were expected and considered in the analysis. The TS' and CS' thicknesses were measured from the images by taking the vertical position of the backwall's brightest pixel as the thickness estimate [11], [14] and considered in the analysis.

The differences in image quality were used to infer differences between the software; namely, to enumerate potential issues with the evaluated software and signal and image processing techniques potentially used by the standard software but not by the evaluated one. The information presented above and in the literature was considered for this purpose.

\section{RESULTS AND DISCUSSION}

The TS' standard and evaluated images in Figure 3 both show a backwall and multiple-reflection artifacts. The backwalls are the 200-250 mm deep objects. The backwall was recognizable in both images because it was a bright and wide object at depths roughly the concrete element's as-built thickness $(240.50 \mathrm{~mm})$. Its brightness is due to the slabbase course interface's large reflection coefficient, and its width is due to the interface being sensed by every ${ }_{\mathrm{T}} \mathrm{r}_{\mathrm{R}}$ pair. The standard image's backwall seems larger than the evaluated image's one because the former is presumably saturated.
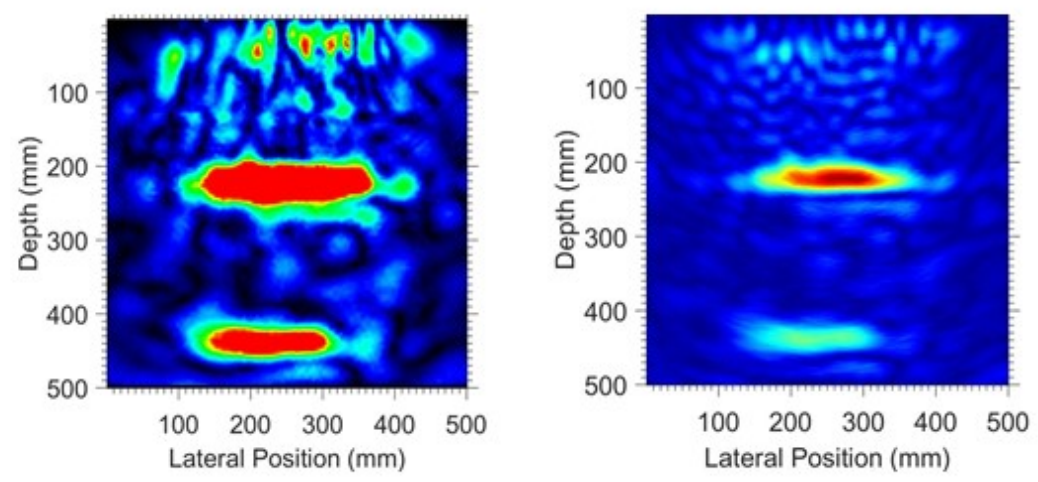

Figure 3. Standard (left) and evaluated (right) images of a TS' point.

The multiple-reflection artifacts are the $425-475 \mathrm{~mm}$ deep objects (Figure 3). As the SAFT does not recognize multiple reflections, the waves bouncing between backwall and surface (multiple reflections) are computed as reflections at ever deeper backwalls and represented as mirror images of the backwall. The mirror images are not carbon copies of the backwall due to attenuation.

The CS' standard images in Figures 4-6 show a dowel, a backwall, and multiple-reflection artifacts, and its evaluated images shown a dowel, a backwall, surface-waves artifacts and multiple-reflection artifacts. The backwall was recognizable in every image. The multiple-reflection artifacts comprise mirror images of the backwall and dowel.

The dowel is bright, round, and at the expected position in the evaluated images and bright and at the expected position, but not round, in the standard ones (Figures 4-6). The dowels were nevertheless recognizable in every image. The shape information on the mirror images in the standard images were used to recognize the dowels. Artifacts, if well understood, might therefore provide some information on the inspected structure. 

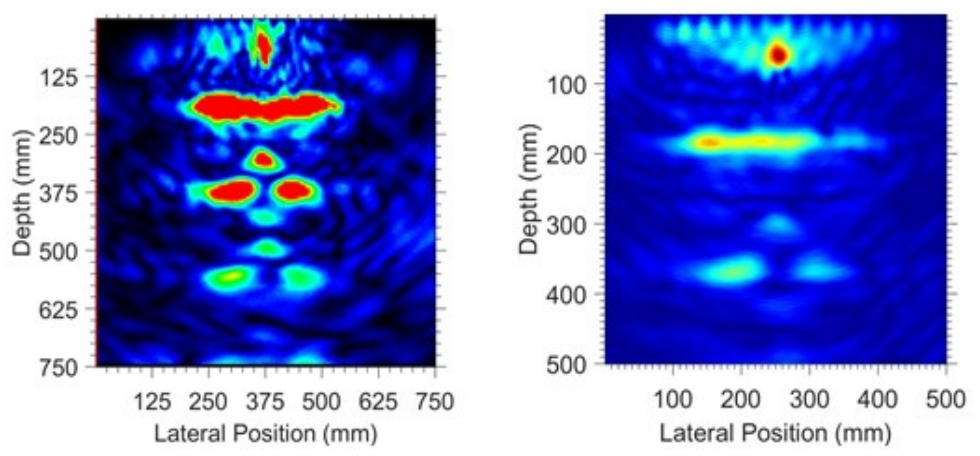

Figure 4. Standard (left) and evaluated (right) images of a CS' point over the $54 \mathrm{~mm}$-deep dowel.
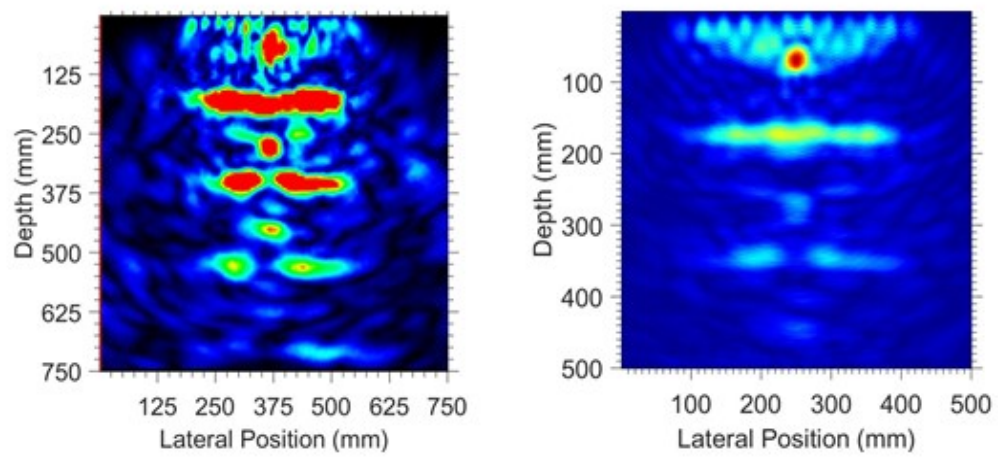

Figure 5. Standard (left) and evaluated (right) images of a CS' point over the $74 \mathrm{~mm}$-deep dowel.
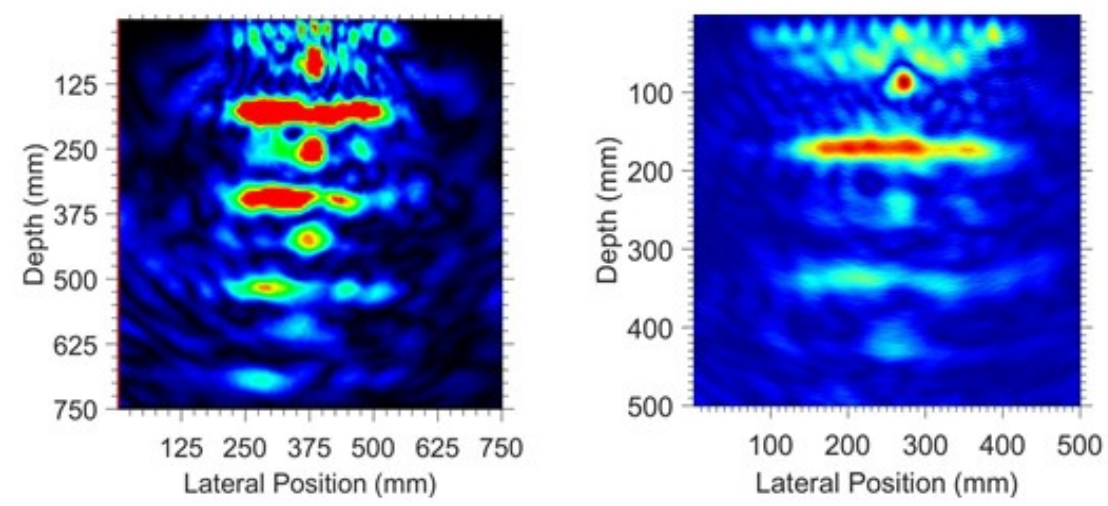

Figure 6. Standard (left) and evaluated (right) images of a CS' point over the $94 \mathrm{~mm}$-deep dowel.

The backwalls should be shown brighter than the dowels since the slab-base course interface's reflection coefficient is larger than the slab-dowel's coefficient. Attenuation prevented this in the evaluation images in Figures 4-6. The ${ }_{\mathrm{T}}$-backwall path is larger than the ${ }_{\mathrm{T}}$-dowel path. Hence, the waves striking the backwall have smaller intensity, and the waves reflected at the backwall might have smaller intensity despite the backwall's larger reflection coefficient. In addition, the waves reflected at the backwall are attenuated to a greater degree on their way to $\mathrm{R}$. As a result of this and the fact that attenuation has not been compensated in the evaluated software, the dowels are shown brighter than the backwall in the evaluated images. 
The dowels and backwalls have similar brightness in the standard images in Figures 4-6 due to saturation and presumably attenuation compensation. The multiple-reflection artifacts in the standard images are brighter and wider in Figures 3-6 for the same reasons.

The surface-waves artifacts are shown above the dowels in the evaluated images in Figures 4-6. As the SAFT does not recognize surface waves, it computes the waves travelling on the concrete structure's surface from ${ }_{T}$ to ${ }_{R}$ as reflected waves in the inspected volume's interior, resulting in those artifacts. The surface waves are unavoidable. The brightness distribution in Figure 3 occluded them. The standard software has presumably filtered them out as the artifacts are not presented in the standard images in Figures 4-6.

The TS and CS were roughly $220 \mathrm{~mm}$ and $170 \mathrm{~mm}$ thick respectively according to Figures 3-6. As the same thickness measure was obtained with the standard and evaluated images, the evaluated software does not result in gross quantitative errors for the inspected scenarios. The thickness estimates' inaccuracy was due to the ${ }_{c}$ estimates' inaccuracy. The ${ }_{c}$ estimate's accuracy was disregarded for this work.

The standard and evaluated images obtained for the other points are presented in Figures 7-11. The observations above are therefore true for all standard and evaluated images obtained int this work. Mode-conversion artifacts were not observed in this work because shear-horizontal waves are not mode converted. Acoustic shadowing was not observed in this work either, despite being reported for similar scenarios [4].
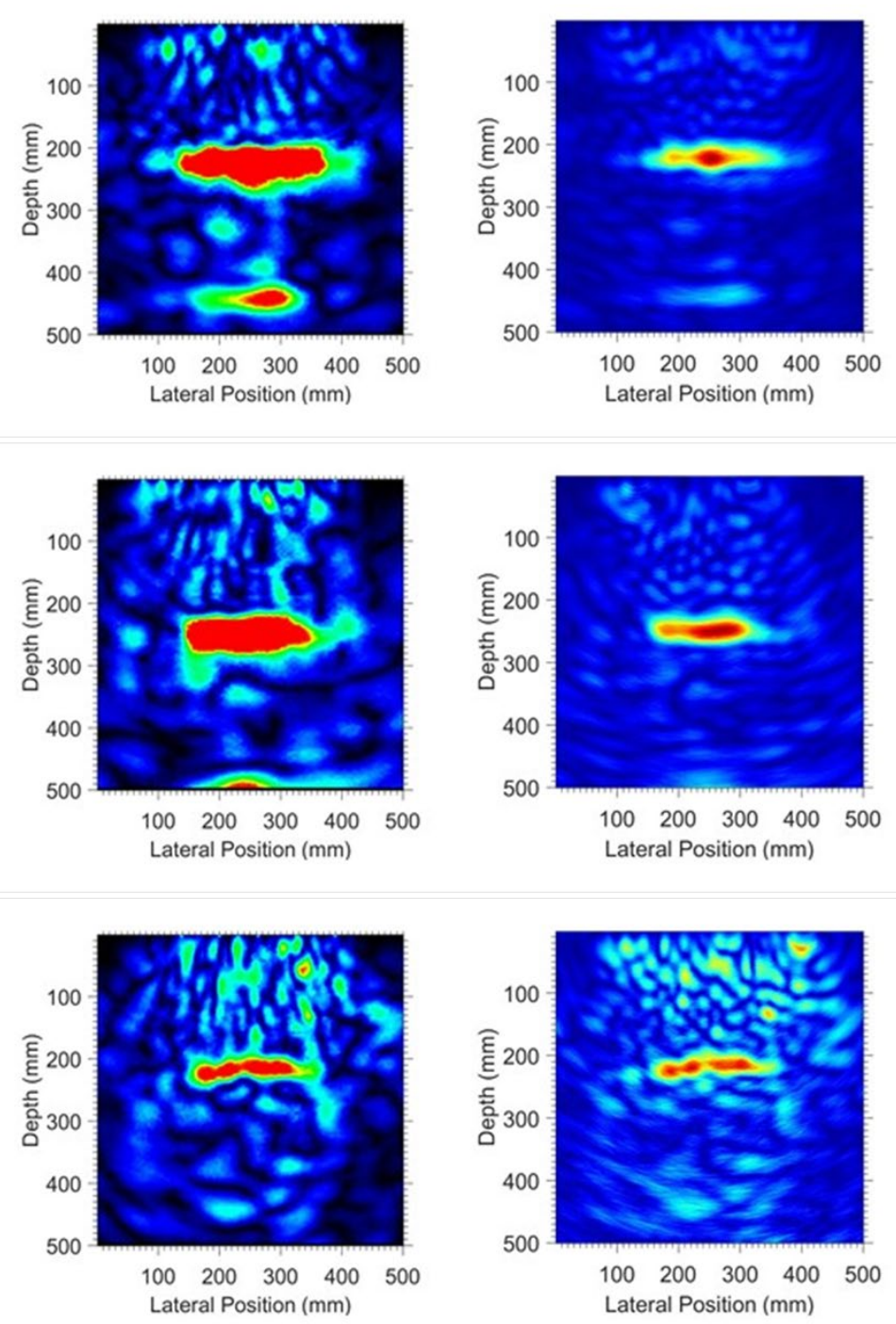

Figure 7. Standard (left) and evaluated (right) images of the other TS' points (Part 1). 

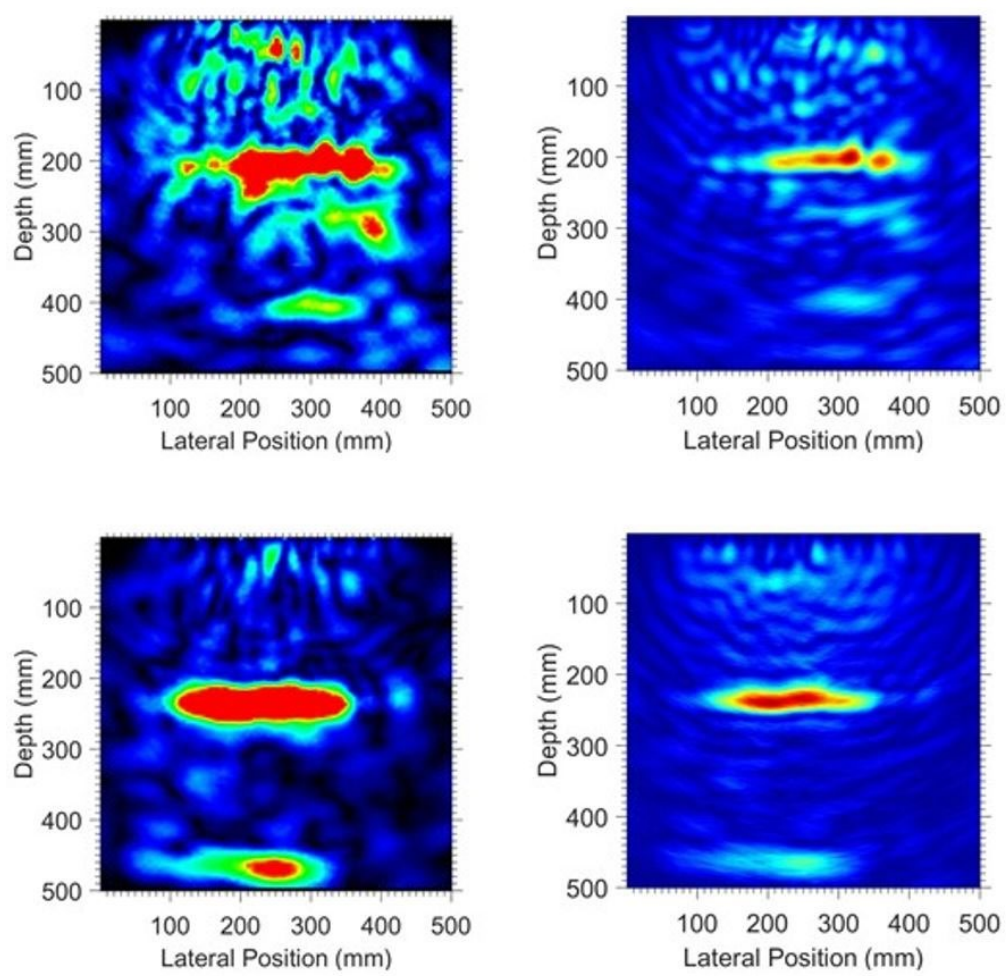

Figure 8. Standard (left) and evaluated (right) images of the other TS' points (Part 2).
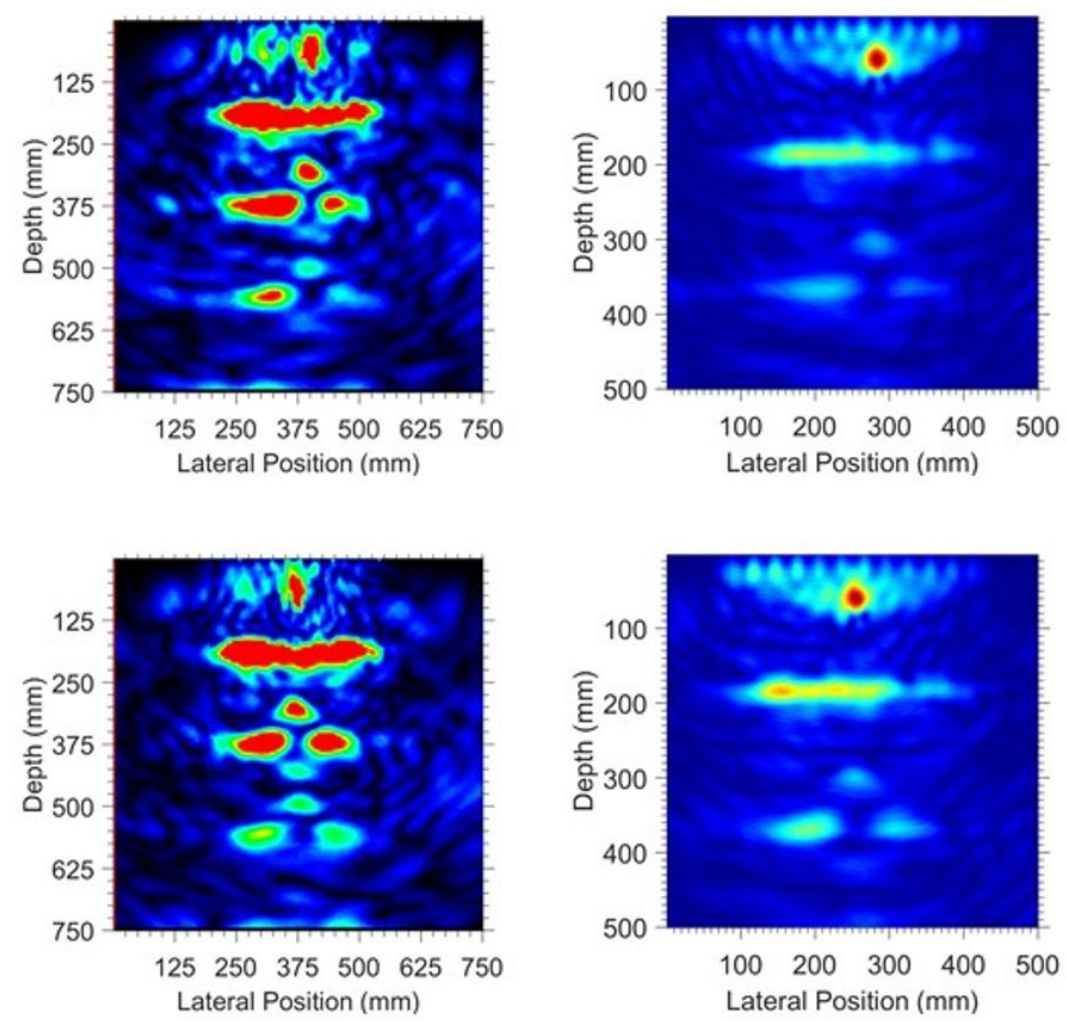

Figure 9. Standard (left) and evaluated (right) images of the other CS' points over the $54 \mathrm{~mm}$-deep dowel. 

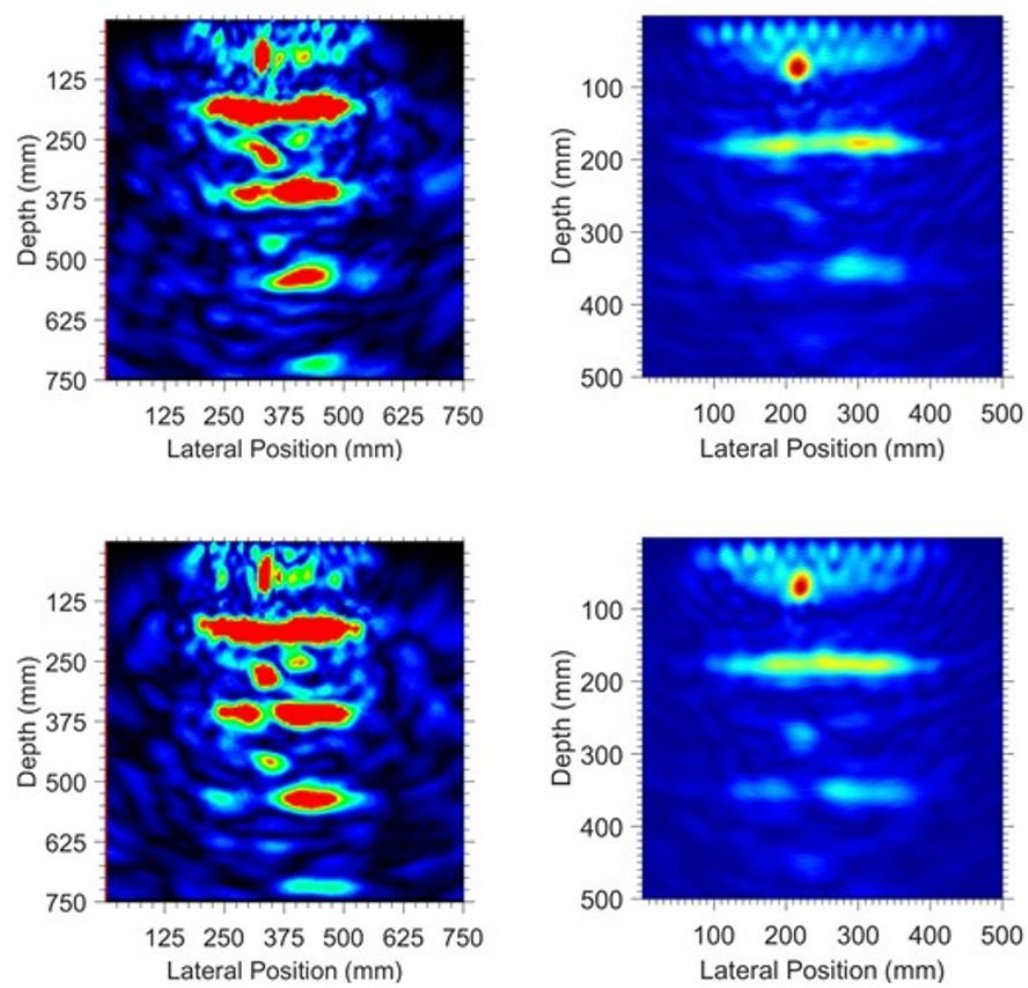

Figure 10. Standard (left) and evaluated (right) images of the other CS' points over the $74 \mathrm{~mm}$-deep dowel.
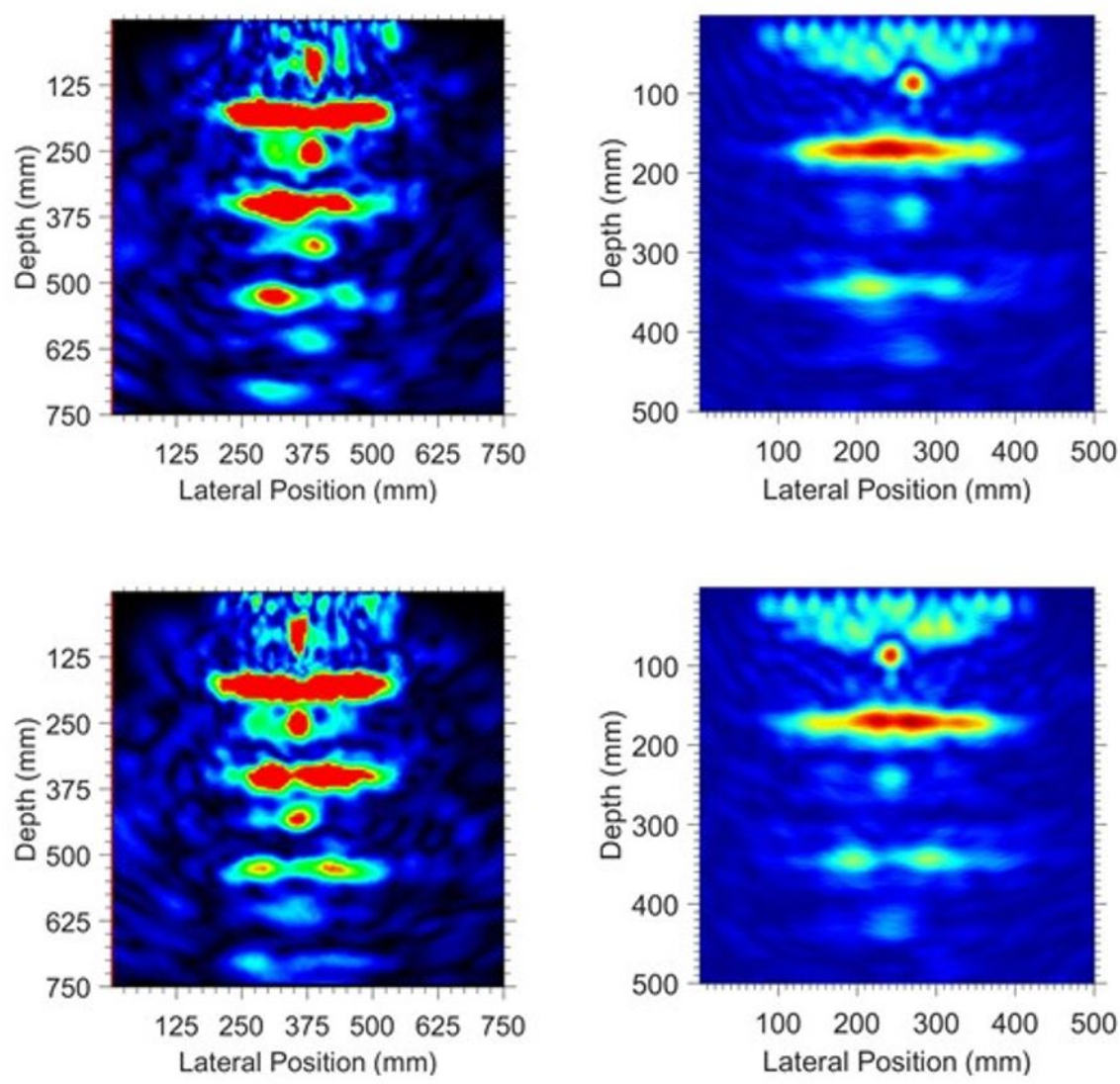

Figure 11. Standard (left) and evaluated (right) images of the other CS' points over the $94 \mathrm{~mm}$-deep dowel. 


\section{CONCLUSIONS}

A SAFT UI software for JPCP NDE was developed and validated in this work. The SAFT's fundamentals were reviewed and every step required to implement the SAFT was discussed. The validation was carried out by comparing the JPCP images obtained with the herein developed software to the ones obtained with a software assumed to yield standard images. The backwalls and dowels (steel bars) were recognizable in both evaluated and standard images. The characteristic of these objects and artifacts in both images were discussed and considered in the validation. The thickness estimated from the evaluated and standard images were the same. Therefore, from a practical standpoint, the quality of the images obtained with the herein developed software and the standard one was essentially the same and no gross quantitative errors were observed in the evaluated images. The differences between the evaluated and standard images were presumably due to further signal and image processing steps in the standard software and not due to errors in the evaluated software. The herein developed software was therefore validated for JPCP NDE, though restricted to the scenarios represented by the inspected structures. The software can nevertheless be used for testing and development of solutions to tackle SAFT UI's issues.

\section{LIST OF SYMBOLS}

c: Pulse velocity.

$f_{i}(x, y), f(x, y)$ : Reconstruction grid or image.

$g(t), g_{i}(t)$ : Time-domain signal.

$\mathrm{P}(\mathrm{x}, \mathrm{y})$ : Reconstruction grid element or pixel.

$\mathrm{R}_{\mathrm{i}}\left(\mathrm{x}_{\mathrm{R}}, \mathrm{y}_{\mathrm{R}}\right)$ : Position of transducer in reception mode.

$\mathrm{T}_{\mathrm{i}}\left(\mathrm{x}_{\mathrm{T}}, \mathrm{y}_{\mathrm{T}}\right)$ : Position of transducer in transmission mode.

$t_{d}$ : System's time delay.

$\mathrm{w}_{\mathrm{i}}(\mathrm{x}, \mathrm{y})$ : Windowing function.

\section{LIST OF ABBREVIATIONS}

CS: Concrete Specimen

NDE: Nondestructive Evaluation

JPCP: Jointed Plain Concrete Pavement

SAFT: Synthetic Aperture Focusing Technique

SNR: Signal-to-Noise Ratio

TS: Test Section

UI: Ultrasound Imaging

\section{CitATIONS}

[1] D. M. McCann and M. C. Forde, "Review of NDT methods in the assessment of concrete and masonry structures," NDT Int., vol. 34, no. 2, pp. 71-84, Mar 2001, http://dx.doi.org/10.1016/S0963-8695(00)00032-3.

[2] S. R. Doctor, T. E. Hall, and L. D. Reid, "SAFT: the evolution of a signal processing technology for ultrasonic testing," NDT Int., vol. 19, no. 3, pp. 163-167, Jun 1986, http://dx.doi.org/10.1016/0308-9126(86)90105-7.

[3] M. Schickert, M. Krause, and W. Müller, "Ultrasonic imaging of concrete elements using reconstruction by synthetic aperture focusing technique," J. Mater. Civ. Eng., vol. 15, no. 3, pp. 235-246, Jun 2003, http://dx.doi.org/10.1061/(ASCE)08991561(2003)15:3(235).

[4] K. Hoegh, L. Khazanovich, and H. T. Yu, "ultrasonic tomography for evaluation of concrete pavements," Transp. Res. Rec., vol. 2232, no. 1, pp. 85-94, Jan 2011, http://dx.doi.org/10.3141/2232-09.

[5] K. Hoegh, L. Khazanovich, B. J. Worel, and H. T. Yu, "Detection of subsurface joint deterioration: blind test comparison of ultrasound array technology with conventional nondestructive methods," Transp. Res. Rec., vol. 2367, no. 1, pp. 3-12, Jan 2013, http://dx.doi.org/10.3141/2367-01.

[6] L. S. Salles, J. T. Balbo, and L. Khazanovich, "Non-destructive ultrasonic tomography for concrete pavement evaluation: signal processing and image analysis of crucial parameters," Rev. IBRACON Estrut. Mater., vol. 10, no. 6, pp. 1182-1191, Nov 2017, http://dx.doi.org/10.1590/s1983-41952017000600004.

[7] L. S. de Salles, L. Khazanovich, and J. T. Balbo, "Non-destructive evaluation of crack initiation and propagation in continuously reinforced concrete pavements," Transp. Res. Rec., vol. 2673, no. 3, pp. 375-385, Mar 2019, http://dx.doi.org/10.1177/0361198119833672. 
[8] M. Krause, F. Mielentz, B. Milman, W. Müller, V. Schmitz, and H. Wiggenhauser, "Ultrasonic imaging of concrete members using an array system," NDT Int., vol. 34, no. 6, pp. 403-408, Sep 2001, http://dx.doi.org/10.1016/S0963-8695(01)00007-X.

[9] P. Shokouhi, J. Wolf, and H. Wiggenhauser, "Detection of delamination in concrete bridge decks by joint amplitude and phase analysis of ultrasonic array measurements," J. Bridge Eng., vol. 19, no. 3, pp. 04013005, Mar 2014, http://dx.doi.org/10.1061/(ASCE)BE.1943-5592.0000513.

[10] H. Choi, J. Bittner, and J. S. Popovics, "Comparison of ultrasonic imaging techniques for full-scale reinforced concrete," Transp. Res. Rec., vol. 2592, no. 1, pp. 126-135, Jan 2016, http://dx.doi.org/10.3141/2592-14.

[11] H. L. L. Seiffert, "Assessment of the accuracy of an ultrasound imaging system for the measurement of the thickness of pavements' concrete slabs,” M.S. thesis, Univ. São Paulo, São Paulo, 2019.

[12] K. Hoegh and L. Khazanovich, "Extended synthetic aperture focusing technique for ultrasonic imaging of concrete," NDT Int., vol. 74, pp. 33-42, Sep 2015, http://dx.doi.org/10.1016/j.ndteint.2015.05.001.

[13] J. Bittner and J. Popovics, "Ultrasonic analysis modifications for imaging of concrete infrastructure," in 2017 IEEE International Ultrasonics Symposium (IUS), Washington, DC, Sep. 2017, pp. 1, https://doi.org/10.1109/ULTSYM.2017.8091747.

[14] J. A. Bittner, A. Spalvier, and J. S. Popovics, "Internal imaging of concrete elements," Concr. Int., vol. 40, no. 4, pp. 57-63, Jan 2018.

[15] J. A. Jensen, S. I. Nikolov, K. L. Gammelmark, and M. H. Pedersen, "Synthetic aperture ultrasound imaging," Ultrasonics, vol. 44, pp. e5-e15, Dec 2006., http://dx.doi.org/10.1016/j.ultras.2006.07.017.

[16] M. Spies and H. Rieder, "Synthetic aperture focusing of ultrasonic inspection data to enhance the probability of detection of defects in strongly attenuating materials," NDT Int., vol. 43, no. 5, pp. 425-431, Jul 2010., http://dx.doi.org/10.1016/j.ndteint.2010.04.002.

[17] M. Spies, H. Rieder, A. Dillhöfer, V. Schmitz, and W. Müller, "Synthetic aperture focusing and time-of-flight diffraction ultrasonic imaging: past and present," J. Nondestruct. Eval., vol. 31, no. 4, pp. 310-323, Dec 2012., http://dx.doi.org/10.1007/s10921-012-0150$z$.

[18] J. Prager, J. Kitze, C. Acheroy, D. Brackrock, G. Brekow, and M. Kreutzbruck, "SAFT and TOFD: a comparative study of two defect sizing techniques on a reactor pressure vessel mock-up," J. Nondestruct. Eval., vol. 32, no. 1, pp. 1-13, Mar 2013., http://dx.doi.org/10.1007/s10921-012-0153-9.

[19] V. Schmitz, S. Chakhlov, and W. Müller, "Experiences with synthetic aperture focusing technique in the field," Ultrasonics, vol. 38, no. 1-8, pp. 731-738, Mar 2000. http://dx.doi.org/10.1016/S0041-624X(99)00219-X.

[20] S. H. Contreras Ortiz, T. Chiu, and M. D. Fox, "Ultrasound image enhancement: a review," Biomed. Signal Process. Control, vol. 7 , no. 5, pp. 419-428, Sep 2012, http://dx.doi.org/10.1016/j.bspc.2012.02.002.

[21] H. L. L. Seiffert and J. T. Balbo, "Suppression of surface waves with the ensemble empirical mode decomposition to enhance ultrasound images of reinforced concrete elements," NDT Int., vol. 116, pp. 102329, Dec 2020, http://dx.doi.org/10.1016/j.ndteint.2020.102329.

[22] X. Guan, J. He, and E. M. Rasselkorde, "A time-domain synthetic aperture ultrasound imaging method for material flaw quantification with validations on small-scale artificial and natural flaws," Ultrasonics, vol. 56, pp. 487-496, Feb 2015, http://dx.doi.org/10.1016/j.ultras.2014.09.018.

[23] S. Kramer, "Ultrasonic weld defect sizing using the synthetic aperture focusing technique," in Review of Progress in Quantitative Nondestructive Evaluation, D. O. Thompson and D. E. Chimenti, Eds. Boston, MA: Springer US, 1989, pp. 1995-2002. http://dx.doi.org/10.1007/978-1-4613-0817-1_253.

[24] J. T. Balbo, Pavimentos de Concreto. São Paulo: Oficina de Textos, 2009.

Author contributions: HLLS: methodology, software, validation, formal analysis, writing. JTB: conceptualization, methodology, resources, supervision.

Editors: Vladimir Haach, Guilherme Aris Parsekian. 